\title{
ARTIGO
}

DOI: https://doi.org/10.22481/praxis.v14i29.4107

\section{POLÍTICAS PÚBLICAS PARA INSERÇÃO PROFISSIONAL DE JOVENS EM MANAUS: DESAFIOS À PESQUISA EM EDUCAÇÃO}

\author{
PUBLIC POLICIES FOR THE PROFESSIONAL INSERTION OF YOUNG PEOPLE IN \\ MANAUS: CHALLENGES TO RESEARCH IN EDUCATION
}

\author{
POLÍTICAS PÚBLICAS PARA INSERCIÓN PROFESIONAL DE JÓVENES EN \\ MANAUS: DESAFÍOS A LA INVESTIGACIÓN EN EDUCACIÓN
}

\author{
Nádia Maciel Falcão \\ Universidade Federal do Amazonas - Brasil \\ Rafaela Silva Marinho \\ Universidade Federal do Amazonas - Brasil
}

\begin{abstract}
Resumo: Apresenta resultados de investigações relacionadas às políticas públicas de juventude implementadas pelas Secretarias de Juventude de âmbito estadual (Amazonas) e Municipal (Manaus), com foco nas ações voltadas para a inserção profissional de jovens e aponta questões relacionadas à temática que são importantes para a composição da agenda da pesquisa científica sobre a educação na realidade amazônica. Os dados decorrem da análise de documentos relacionados aos programas, projetos e outras ações propostas no período de 2005 a 2016 pelos órgãos do poder público estadual do Amazonas e do Município de Manaus, responsáveis pela promoção de políticas públicas para esse segmento da população. O mapeamento das ações e o levantamento das concepções de juventude que fundamentam as políticas públicas de juventude no cenário local, oportunizados pelos estudos realizados, indica a permanência de ações descontínuas e fragmentadas, além de tecnicamente frágeis, refletindo pouca compreensão da noção do jovem enquanto sujeito de direito, a qual vem sendo disputada no cenário político e acadêmico como alternativa de superação da noção de juventude enquanto problema social e fase de mera transição.
\end{abstract}

Palavras-chave: Inserção Profissional. Pesquisa em Educação. Políticas públicas de juventude.

\begin{abstract}
It presents results of investigations related to the youth public policies implemented by the state youth secretariats (Amazonas) and Municipal (Manaus), focusing on the actions aimed at the insertion of youth professionals and points out issues related to the theme that are important for the composition of the agenda of scientific research on education in the Amazonian reality. The data comes from the analysis of documents related to the programs, projects and other actions proposed in the period from 2005 to 2016 by the state public authorities of Amazonas and the Municipality of Manaus, responsible for promoting public policies for this segment of the population. The mapping of actions and the survey of the conceptions of youth that underlie the public policies of youth in the local scenario, facilitated by the studies carried out, indicates the permanence of discontinuous and fragmented actions, in addition to being technically fragile, reflecting little understanding of the notion of youth as subject of law, which has been disputed in the political and academic scenario as an alternative to overcoming the notion of youth as a social problem and a mere transition phase.
\end{abstract}


Keywords: Professional Insertion. Public Policies of Youth. Search in Education.

Resumen: En el presente trabajo se analizan los resultados de las investigaciones sobre las políticas públicas de juventud implementadas por las Secretarías de Juventud de ámbito estatal (Amazonas) y Municipal (Manaus), con foco en las acciones dirigidas a la inserción profesional de jóvenes y apunta cuestiones relacionadas a la temática que son importantes para la composición de la agenda de la investigación científica sobre la educación en la realidad amazónica. Los datos se derivan del análisis de documentos relacionados a los programas, proyectos y otras acciones propuestas en el período de 2005 a 2016 por los órganos del poder público estadual del Amazonas y del Municipio de Manaus, responsables de la promoción de políticas públicas para ese segmento de la población. El mapeo de las acciones y el levantamiento de las concepciones de juventud que fundamentan las políticas públicas de juventud en el escenario local, oportunistas por los estudios realizados, indica la permanencia de acciones discontinuas y fragmentadas, además de técnicamente frágiles, reflejando poca comprensión de la noción del joven como sujeto de derecho, la cual viene siendo disputada en el escenario político y académico como alternativa de superación de la noción de juventud como problema social y fase de mera transición.

Palabras clave: Inserción Profesional. Búsqueda en Educación. Políticas Públicas de la Juventud.

\section{Introdução}

O artigo discute a configuração das políticas públicas de juventude no cenário local, debruçando-se sobre a realidade da Cidade de Manaus. Explora dados da pesquisa "Juventude, Políticas Públicas e Ensino Médio: diversidades e desafios amazônicos", desenvolvida no período de 2014 a 2016, junto às Secretarias de Juventude de âmbito estadual (Amazonas) e Municipal (Manaus).

A pesquisa está vinculada ao Programa de Pós-graduação em Educação - PPGE da UFAM e contempla diferentes metas voltadas à investigação das políticas públicas destinadas aos jovens. Exploram-se principalmente os resultados de dois subprojetos, a saber: "Políticas Públicas de Juventude em Manaus: mapeamento das ações e análise da concepção de juventude" e "Políticas Públicas para inserção profissional de jovens: ações da Secretaria Municipal de Juventude, Esporte e Lazer do Município de Manaus”.

Ambas as investigações caracterizam-se como estudos de base documental, nos quais se realizou o levantamento de documentos que evidenciam as ações desenvolvidas pelas secretarias de juventude do Estado do Amazonas e do Município de Manaus no período pesquisado (2005-2016), tais como relatórios, projetos e também a legislação.

A análise dos documentos fundamentou-se na perspectiva qualitativa, que permitiu, além do mapeamento das ações, a compreensão da concepção de juventude que sustenta as 
ações e a compreensão da realidade local diante das configurações das políticas públicas de juventude no cenário nacional.

Na organização do artigo dedicam-se as seções iniciais à revisão de concepções e de alguns aspectos históricos considerados importantes para a compreensão das políticas públicas de juventude enquanto objeto de estudo da área da educação e que também contribuem para a análise dos resultados das pesquisas e considerações finais, os quais constituem as seções finais deste trabalho.

\section{Políticas Públicas de Juventude no Brasil}

A introdução da juventude na agenda pública brasileira enquanto grupo que demanda políticas públicas específicas se observa a partir do final dos anos 1980, conduzida inicialmente pela preocupação em controlar problemas de saúde, violência e desemprego que incidiam principalmente sobre essa população (SPOSITO e CARRANO, 2003).

Essa configuração produziu uma noção problemática que fazia recair sobre os sujeitos jovens os estigmas de problemas sociais que eram reflexos de questões mais amplas, inerentes ao próprio modelo de desenvolvimento das sociedades capitalistas. Nessa abordagem que predominou nas primeiras políticas públicas de juventude o jovem é tomado como problema social.

Segundo Sposito e Corrochano (2005), o que está na base dessa interpretação é a prevalência da violência como questão de fundo da constituição de uma opinião pública sobre os jovens nos anos 1990, pois, como observam as autoras, mesmo quando se propõem políticas públicas de enfrentamento de outros problemas que acometem os jovens, a exemplo do desemprego, o argumento de que jovem com tempo livre é jovem potencialmente perigoso está presente na maioria das propostas.

Com relação às políticas públicas de juventude direcionadas aos jovens de Manaus, o trabalho de Falcão (2016) aponta os fortes resquícios da noção do jovem como problema social, ao mesmo tempo em que iniciativas que sinalizam para o reconhecimento do jovem como sujeito de direitos esbarram nos problemas da falta de continuidade e na fragmentação.

Acerca das políticas públicas de juventude, Novaes (2009) ressalta a importância de que estas políticas considerem as peculiaridades desse segmento da população, articulem-se à realidade social e valorizem a diversidade das juventudes brasileiras. Na compreensão da 
autora as políticas públicas de juventude podem ser classificadas em três tipos: universais, atrativas e exclusivas.

Dentre as políticas classificadas como universais estão as políticas dirigidas à toda a população, que também contemplam segmentos específicos, dentre os quais os jovens e que se referem, por exemplo, às políticas de trabalho e emprego, políticas educacionais, políticas de assistência social, políticas de saúde e etc.

Nas políticas atrativas se enquadram políticas que não são dirigidas somente aos jovens, mas que incidem sobre eles por diferentes aspectos e no geral apresentam caráter emergencial ou experimental, ou os dois ao mesmo tempo.

As políticas exclusivas são aquelas voltadas para uma determinada faixa etária, no caso das políticas de juventude a idade definida na legislação brasileira é de 15 a 29 anos. As políticas exclusivas podem abranger diferentes áreas tais como saúde, trabalho, educação, cultura, desenvolvimento social, segurança entre outros. Contudo, "via de regra, constituemse em programas e ações emergenciais para jovens excluídos ou em situações de exclusão desfavorável" (NOVAES, 2009, p.20).

Para Sposito e Carrano (2003, p. 19) "é preciso reconhecer que histórica e socialmente, a juventude tem sido considerada como fase de vida marcada por uma certa instabilidade associada a determinados 'problemas sociais' [...]” Nesse sentido, a concepção do jovem como problema social ou indivíduo vulnerável teve forte influência sobre as ações, voltadas para as questões juvenis, de órgão e entidades não governamentais e governamentais nas décadas de 1980 e 1990.

Os estudos sobre as políticas públicas de juventude apontam a partir dos anos 2000 uma "tendência de superação das visões mais restritas do jovem e o fortalecimento de seu entendimento como sujeito de direitos e da juventude como uma fase da vida que apresenta demandas e significados específicos" (FALCÃO, 2016, p.125). Em contrapartida se observa uma dissimetria na compreensão deste sentido de juventude pelas diferentes esferas públicas, além de outros problemas recorrentes nas políticas públicas como a descontinuidade e fragmentação.

O ano de 2005 é considerado o marco da política pública de juventude em âmbito nacional, dado o delineamento da Política Nacional de Juventude ocorrido naquele ano e expresso na criação do Conselho Nacional de Juventude (CONJUVE), da Secretaria Nacional de Juventude (SNJ) e do Programa Nacional de Inclusão de Jovens (ProJovem), em sua primeira versão, por meio da Lei ${ }^{\circ} 11.129$ de 30 de junho de 2005 . 
Na compreensão de Araújo (2014), a criação do Conselho Nacional de Juventude (CONJUVE), da Secretaria Nacional de Juventude (SNJ) e do Programa Nacional de Inclusão de Jovens (ProJovem), representa um fato importante no entendimento sobre o papel das PPJ's com relação aos jovens no Brasil.

[...] o Estado passa a reconhecer que esse segmento fazia jus a ações do poder público visando não mais solucionar problemas causados por eles, mas sim, construir novas perspectivas e possibilidades voltadas para as áreas sociais visando resgatar e corrigir um débito histórico em relação aos mesmos (ARAÚJO, 2014, p.13).

Apesar do marco importante que a criação das políticas, programas e ações representam para o segmento juvenil, não se pode considerar que apenas o surgimento no espaço público seja capaz de resolver os problemas historicamente acumulados pela população jovem no Brasil.

$\mathrm{Na}$ análise de Novaes (2009), a respeito da criação do Conselho Nacional de Juventude (CONJUVE), da Secretaria Nacional de Juventude (SNJ) e do Programa Nacional de Inclusão de Jovens (ProJovem) é importante saber, “[...] que o prestígio do espaço institucional criado, por si, não é garantia para que se ultrapasse a cultura de políticas setoriais, com suas resistências históricas a modelos de gestão compartilhada e efetiva integração de programas e ações (NOVAES, 2009, p.20)

Contudo, é inegável o avanço nas políticas públicas de juventude no Brasil desde 2005. Entre outras conquistas para o segmento juvenil, destacam-se a inclusão do termo jovem na Constituição Federal (1988) por meio da Emenda Constitucional no 65, de 13 de julho de 2010 e a aprovação do Estatuto da Juventude através da Lei n ${ }^{\circ} 12.852$ de 5 de agosto de 2013.

\section{Políticas Públicas de Juventude para Inserção Profissional de Jovens}

A juventude entendida enquanto fase da vida detentora de peculiaridades tem seus significados afetados pelas transformações sociais e, contemporaneamente, observam-se, na composição da condição juvenil, os reflexos de “[...] importantes alterações ocorridas nas relações e configurações familiares, na educação escolar e nas demandas do mundo do trabalho, dentre outras [...]" (FALCÃO; CARRANO, 2016, p.153). 
A questão da inserção profissional é também um dos temas relevantes para o estudo e a compreensão do segmento juvenil, sobretudo no caso do Brasil. Segundo, Falcão e Carrano (2016) historicamente o trabalho ocupa grande centralidade na vida dos jovens brasileiros, seja pela "realidade imediata" ou "enquanto projeção" (p.157). Ou seja, o trabalho é parte indissociável da situação juvenil e isso permite a investigação dos sentidos que os jovens atribuem a essa categoria.

Alguns dos principais significados do trabalho para os jovens são apontadas por Guimarães (2008) na pesquisa "Perfil da juventude brasileira" realizada no ano de 2003 em 198 municípios, que contou com a participação de 3.051 (três mil e cinquenta e um) entrevistados, entre 15 e 24 anos.

Em seu estudo, Guimarães (2008), aponta que para a juventude brasileira a categoria trabalho aparece: como o assunto de maior interesse, entre os problemas que mais os preocupam, entre as urgências que os mesmos resolveriam na própria vida ou no mundo caso pudessem, e entre os problemas mais importantes do Brasil.

Ainda no estudo é possível encontrar que o trabalho é um assunto de interesse tanto para os jovens que estão inseridos no mercado de trabalho quanto para aqueles que estão à procura de emprego. Além disso, entre educação, segurança e trabalho, este último aparece como assunto de interesse e de muita preocupação para o segmento juvenil.

Segundo a autora, a questão laboral ocupa grande centralidade na vida dos jovens por representar uma necessidade para esse segmento. Desta forma, afirma que,

[...] é sobretudo como fator de risco, desestabilizador das formas de inserção social e padrão de vida, que o trabalho se manifesta como demanda urgente, necessidade, no centro da agenda de parcela significativa da juventude brasileira. Ou, de outra forma, é por sua ausência, por sua falta, pelo nãotrabalho, pelo desemprego, que o mesmo se destaca (GUIMARÃES, 2008, p. 159).

Outra acepção presente na análise da autora é o sentido atribuído ao trabalho pelos jovens como sendo um direito. Para eles a inserção profissional é um dos direitos sociais que mais almejam.

Como dito anteriormente o trabalho faz parte da construção da situação juvenil no país e os estudos apontam para interessantes sentidos atribuídos ao mesmo. Entre tais, a preocupação com o desemprego e a consequente não inserção no mercado de trabalho é uma 
preocupação recorrente da maioria dos jovens. Nesse sentido, é importante saber como se configuram as políticas públicas para a inserção profissional.

Com relação às políticas de juventude voltadas à inserção profissional cabem destacar os estudos de Sposito e Corrochano (2005) que analisam alguns pressupostos orientadores de programas sociais públicos destinados a jovens pobres no Brasil que envolvem transferência de renda.

Com o esboço de três programas selecionas para estudo, algumas semelhanças entre os mesmos refletem a conjuntura das políticas voltadas à inserção juvenil no mercado de trabalho. Dois dos programas eram voltados à inserção profissional, Projeto Agente Jovem de Desenvolvimento Social e Humano e Programa Serviço Civil Voluntário, e apresentavam pontos similares. Dentre tais destacam-se: a preocupação na ocupação dos jovens dificultando seu envolvimento com o mundo do crime e os tirando da condição de vulnerabilidade pessoal e social, além da contrapartida para o recebimento de bolsas, através da realização de cursos complementares e "serviços comunitários".

O terceiro programa, Programa Bolsa Trabalho Renda, tinha como objetivo a ampliação do nível de escolaridade retardando a entrada dos jovens no mercado de trabalho, apesar de não se tratar de um programa voltado a inserção profissional juvenil, também, apresentava questões semelhantes aos outros programas, como por exemplo a prevenção do perigo e da violência.

Ainda sobre os programas abordados, em linhas gerais, as autoras apontam uma forte percepção de contrapartida existente nesses programas. Por um lado, a contrapartida da bolsa (renda estipulada por cada programa) em detrimento de ações comunitárias e cursos complementares e por outro lado a contrapartida no retorno à escola e na realização de atividades de formação de caráter complementar.

O que demonstra a fragilidade com que esses programas por vezes ocorrem. Visto que, entre outros, grande parte dos jovens permaneciam nos programas apenas pela renda oferecida, sem encontrarem sentido e finalidade naquilo que participavam.

Para Corrochano (2014, p.33), atualmente, as escolhas das ações públicas dirigidas aos jovens em relação à inserção profissional enfatizam "o investimento na elevação da escolaridade e no aumento da qualificação das jovens gerações”, deixando de lado questões importantes relacionadas às expectativas almejadas por esse público como a real busca por trabalho em situações de qualidade. 
É importante saber que no conjunto de programas do governo federal não é possível se delinear uma política estrutural de emprego para jovens. Para tanto, Corrochano (2014) destaca:

No campo do trabalho prevalecem programas de caráter focalizado, que não dizem respeito à problemática do trabalho para a juventude como um todo tendo tempo e público determinados. Também não se observa a proposição de ações que considerem a diversidade de relações que a heterogeneidade do segmento juvenil estabelece com o campo do trabalho, o estudo ou com ambas esferas simultaneamente. Aspectos relacionados às condições de trabalho, jornada e salários dos jovens aparecem de maneira muito tímida no debate público e estão ausentes no campo das ações governamentais (CORROCHANO, 2014, p.35).

Portanto, apesar dos consideráveis avanços nas políticas públicas de juventude, existe um longo percurso para que as preocupações e necessidades da população jovem realmente encontre espaço nas ações públicas. E a inserção profissional, que sem dúvidas ocupa parte significativa do interesse desse segmento, necessita de políticas públicas que possibilitem melhores condições de vida a esses indivíduos.

Com isso, é preciso a superação das políticas voltadas à inserção juvenil no mercado de trabalho, que focam, principalmente, a visão restrita de que os jovens desempregados representam perigo para à sociedade. $\mathrm{E}$, se voltem para as expectativas dos jovens quanto à construção do seu presente e os caminhos para um futuro.

\section{Inserção profissional e outros desafios às Políticas Públicas de Juventude na Cidade de Manaus}

Conforme se salientou na primeira seção deste artigo, a incorporação das pautas juvenis na legislação e a institucionalização de setores dentro da estrutura dos poderes federal, estaduais e municipais, são importantes processos no movimento mais amplo de construção das políticas públicas de juventude. Permeados por contradições e dificuldades, registra-se nos anos 2000 o surgimento das secretarias de juventude ou órgãos similares por todo o território nacional.

No Estado do Amazonas e no Município de Manaus o processo de definição de setores específicos da administração pública para propor e implementar as políticas públicas de juventude se pautou na acomodação do setor da juventude junto às pastas do desporto e lazer. Registra-se no ano de 2003 a criação da secretaria de Estado da Juventude, Desporto e Lazer, por meio da Lei Estadual no 2.783, de 31 de janeiro de 2003, e no ano de 2009 a criação da 
Secretaria Municipal de Desporto, Lazer e Juventude - SEMDEJ, por meio da Lei Municipal $\mathrm{n}^{\circ} 1.314$, de 04 de março de 2009.

Desde o surgimento até o período da pesquisa tanto a Secretaria Estadual quanto a Municipal sofreram mudanças no que diz respeito à nomenclatura e organização interna dos setores. Na esfera estadual a Lei $n^{\circ} 4.163$, de 09 de março de 2015 , alterou a nomenclatura do órgão para Secretaria de Estado de Juventude, Esporte e Lazer - SEJEL (Art. 1º I, d, 15).

Na esfera Municipal, depois de uma breve experiência de funcionamento de uma Secretaria exclusiva para a pasta da juventude, entre março de 2010 a julho de 2013, a Lei Delegada $n^{\circ} 01$, de 31 de julho de 2013, volta a reunir a juventude, o esporte e o lazer em uma única secretaria, adotando-se a nomenclatura de Secretaria Municipal de Juventude, Esporte e Lazer - SEMJEL, vigente até o período desta pesquisa. As alterações são complementadas na Lei Delegada ${ }^{\circ} 16$, de 31 de julho de 2013, onde estão dispostas a estrutura organizacional, finalidades e competências da SEMJEL.

A pesquisa buscou inicialmente mapear todas as ações desenvolvidas por ambas as Secretarias no período de 2005 à 2014, para posteriormente proceder à caracterização destas ações quanto ao perfil do público atendido, aos objetivos e atividades, preocupando-se também por apurar o quesito da continuidade dos programas e projetos. Um olhar de aprofundamento também foi lançado sobre as ações da Secretaria de Juventude do Município de Manaus voltadas à temática da inserção profissional, abrangendo o período de 2014 a 2016.

No resultado do mapeamento junto à Secretaria Estadual apurou-se um quantitativo de nove ações relativas ao período de 2008 - 2014, não havendo registros das ações realizadas entre os anos de 2003 a 2007. Na esfera municipal, identificaram-se trinta e seis ações para o período de 2010 a 2014.

$\mathrm{Na}$ análise das ações identificadas se notou para ambas as esferas um maior número de ações voltadas às temáticas do esporte, lazer e educação. Também se observa tanto na esfera estadual quanto municipal a falta de continuidade em grande parte das ações e quanto ao público alvo, o foco nos jovens considerados em condição de vulnerabilidade social.

A noção de vulnerabilidade não conta com referentes claros nos documentos que orientam as políticas públicas de juventude no Estado do Amazonas e no Município de Manaus. Além disso, ao desenvolver ações de modo quase que exclusivo para os jovens nas ditas condições de vulnerabilidade fica descoberto um significativo número de jovens que não 
se encaixam no perfil da vulnerabilidade esperada pelas Secretarias, mas também não dispõem de suportes suficientes para a vivencia da condição juvenil (FALCAO, 2014).

Quanto à concepção de juventude o conjunto das políticas públicas de juventude no cenário local centra-se no entendimento da juventude como fase de crise e transição, geradora de tensões sociais que exigem a atenção do Estado.

$\mathrm{Na}$ busca de aprofundar o olhar acerca da abordagem da SEMJEL/Manaus quanto à inserção profissional, destaca-se incialmente o baixo quantitativo de ações desenvolvidas por esta Secretaria voltadas à temática.

Constatou-se que no total de 57 atividades desenvolvidas pelo Departamento de Juventude da SEMJEL/Manaus no período de 2014-2016, somente 3 se destinavam à questão da inserção profissional: Lançamento do Programa Jovem Empreendedor; II Encontro Municipal de Empreendedorismo Jovem e Assinatura do Convênio minha Primeira Empresa.

O "Lançamento do Programa Jovem Empreendedor" ocorreu no dia 25 de setembro de 2014. O Programa tinha como objetivo levar uma cultura empreendedora para os jovens de Manaus, tendo como viés a cultura do empreendedorismo com a juventude, bem como a capacitação, absorção e encubação de ideias empreendedoras de jovens, como também, o lançamento de seus negócios e o acompanhamento no primeiro ano da empresa (MANAUS/SEMJEL, 2016).

A faixa etária do público alvo do projeto é composta por jovens de 16 a 29 anos, residentes no município de Manaus e com disponibilidade para frequentar os cursos de capacitação oferecidos. O programa destina-se a finalistas do ensino médio, graduandos em cursos ligados à gestão empresarial, pessoas que tenham projetos para empreender, empresários não formalizados e membros da comunidade que almejam ter a sua primeira empresa.

A seleção dos participantes é dividida em duas partes, a primeira é a de divulgação e capacitação empreendedora, na qual se apresenta o funcionamento do programa aos participantes e em seguida seleciona alguns jovens a partir de suas ideias empreendedoras.

E a segunda parte, consiste na participação dos jovens selecionados, que no total seriam seiscentos, em outras etapas no processo de seleção, para que ao final do processo os projetos viáveis (do ponto de vista econômico) recebam uma linha de crédito diferenciada a partir do Banco da Gente ${ }^{1}$.

\footnotetext{
${ }^{1}$ Nome popular do Fundo Municipal de Fomento à Micro e Pequena Empresa (FUMIPEQ), que é administrado pelo Comitê de Crédito Municipal.
} 
Vale destacar que a seleção dos jovens, juntamente com seus projetos empreendedores, cabia à entidade contratada para realizar este serviço, que à época foi a Confederação Nacional de Jovens Empresários (CONAJE), representada pela Associação de Jovens Empresários (AJE/AM), com quem se fez o Convênio, visto que tal entidade possui a propriedade intelectual de um programa que corresponde à demanda do Jovem Empreendedor (RELATÓRIO/SEMJEL, 2017).

A Confederação Nacional de Jovens Empresários - CONAJE é uma entidade sem fins lucrativos, com representação em 24 estados brasileiros, e que atua há 16 anos no fomento ao empreendedorismo, fortalecimento, criação e manutenção de novas empresas principalmente geridas por jovens -, na articulação e divulgação de práticas capazes de fortalecer a disseminação de novos e sólidos negócios no Brasil.

Com foco ainda no jovem empreendedor, a Confederação realiza projetos, eventos e ações para desenvolver empreendedores e jovens líderes por meio de capacitação técnica e experiências diferenciadas, e facilitar a troca de informações e gerar conexões com o objetivo de promover oportunidades de negócios. (CONAJE, 2017)

A Associação de Jovens Empresários do Amazonas é uma entidade criada no ano de 2008. Nasceu dentro da Associação Comercial e tornou-se independente pela diversificação das empresas participantes da rede, a qual conta com o segmento de indústria, comércio e serviço. Objetivando o fomento e consolidação do empreendedorismo jovem, a AJE é filiada à Confederação Nacional de Jovens Empresários - CONAJE - representando uma rede nacional de 36 mil jovens empresários (AJE, 2017).

O "Lançamento do Programa Jovem Empreendedor" (25/09/2014) foi fruto de uma parceria da Prefeitura de Manaus por meio da Secretaria Municipal de Juventude, esporte e lazer (SEMJEL), com a Associação de Jovens Empresários - AJE Amazonas. Consistiu na assinatura de um convênio entre a SEMJEL e a AJE, sendo esta representante da Confederação Nacional de Jovens Empresários (CONAJE), para que em 2015, no ano seguinte ao lançamento, os jovens manauaras, que cumprissem todos os requisitos pudessem participar do "Programa Minha Primeira Empresa" (nome intitulado e copiado na íntegra da entidade detentora da propriedade intelectual do programa a CONAJE).

A SEMJEL fez parceria, também, com Secretaria Municipal do Trabalho, Emprego e Desenvolvimento (SEMTRAD) que por contar com o apoio do Banco da Gente e por ser este um órgão de fomento, poderia dar continuidade ao programa, que no caso seria o 
financiamento dos projetos selecionados, mais precisamente o apoio aos projetos selecionados por meio de uma linha de crédito diferenciado. Desta forma a SEMJEL seria responsável, apenas, pelo acompanhamento do processo (RELATÓRIO/SEMJEL, 2017).

Contudo, ao final do processo, a SEMTRAD não conseguiu concluir o processo e solicitou o fim do acordo e a devolução dos autos à SEMJEL para a devida realização, sendo que à época cabia a SEMJEL apenas o acompanhamento do processo. Por conta disto, no ano de 2015 o programa não foi realizado (RELATÓRIO/SEMJEL, 2017).

A segunda ação foi o "II Encontro Municipal de Empreendedorismo Jovem", e ocorreu no dia 17 de março de 2016. O evento teve como principais objetivos, trazer uma cultura empreendedora aos jovens da cidade de Manaus; mostrar uma outra via de estabilidade econômica por meio da geração de renda conquistada por suas ideias criativas e inovadoras; e despertar o conceito empreendedor, que vai além de empregado e empregador (RELATÓRIO/SEMJEL, 2017).

O evento tinha como público alvo jovens estudantes secundaristas ou universitários; jovens lideranças políticas e da sociedade civil; empreendedores em geral; empresários; executivos; autônomos de todos os segmentos; entidades e especialistas relacionados ao empreendedorismo; membros dos governos ligados à área de Educação, Indústria e Comércio, Desenvolvimento da Ciência e Tecnologia e Desenvolvimento Econômico (RELATÓRIO/SEMJEL, 2017).

O "II Encontro Municipal de Empreendedorismo Jovem" teve como tema: como empreender em tempos de crises. E foi fruto da primeira versão do evento que ocorreu no ano de 2013. Porém, não há mais informações precisas sobre o evento, como o quantitativo de pessoas que participaram e uma avaliação geral do evento.

E por fim, a terceira ação identificada no levantamento de dados foi a "Assinatura do Convênio Minha Primeira Empresa", que ocorrera no dia 01 de julho de 2016. Vale destacar que a assinatura consistiu num ato simbólico e que o programa Minha Primeira Empresa, possui os mesmos objetivos, público alvo e estratégia metodológica do programa Jovem Empreendedor, citado anteriormente.

Sendo assim, esse ato simbólico compreende a mesma ação do Jovem Empreendedor, e contempla exatamente a assinatura do Convênio para o Programa Minha Primeira Empresa, conveniando com a empresa que detém expertise do programa, que é a Confederação Nacional de Jovens Empresários representada pela Associação de Jovens Empresários do Amazonas - AJE/AM. 
A CONAJE já aplica esse programa no estado de Goiás e em Teresina, então a SEMJEL exploraria essa expertise para realizar este serviço, pois conforme os documentos o quadro técnico da prefeitura não supriria esta demanda (RELATÓRIO/SEMJEL, 2017).

De acordo com a CONAJE, o objetivo do programa é incentivar a criação e formalização de novas empresas, com planejamento, acesso ao crédito e acompanhamento técnico do desenvolvimento do negócio, proporcionando, aos potenciais empreendedores, condições mais competitivas de inserção no mercado e contribuindo para o processo de emancipação social.

Conforme a descrição do programa disponibilizada pela SEMJEL à cargo da CONAJE - AJE/AM, fica a divulgação e a capacitação dos jovens selecionados com ideias empreendedoras, para após isto conseguir linha de crédito específica através do Banco da Gente, que é órgão de fomento do município para microempreendedores. E por fim, ainda compete a entidade o acompanhamento durante um ano dos empreendimentos iniciados, para que após isto os novos empreendedores caminhem sozinhos (RELATÓRIO/SEMJEL, 2017).

Os documentos acerca dessa terceira ação registram que apesar da Secretaria Municipal de Juventude, Esporte e Lazer (SEMJEL) separar, empenhar e bloquear o valor necessário para executar a ação, por 2016 ser um ano eleitoral, não foi possível executar a mesma. Posto que quando o extrato do convênio foi enviado ao Diário Oficial para publicação e devida validação do mesmo, a assessoria de atos legislativos alertou a SEMJEL, solicitando que fosse enviado à Procuradoria Geral do Município (PGM), a qual, por sua vez, orientou que não executasse a ação em 2016 devido à questão da vedação eleitoral, que proíbe a realização de novos convênios em anos eleitorais. Sendo assim, houve apenas a assinatura do convênio, porém este não pôde ser colocado em prática (RELATÓRIO/SEMJEL, 2017).

No conjunto estes resultados das pesquisas realizadas junto às Secretarias de juventude em âmbito local, apontam aspectos importantes para a compreensão da configuração das políticas públicas de juventude no cenário local, delineando ao mesmo tempo desafios à pesquisa sobre juventude na área da educação.

Conforme se relatou anteriormente a maioria das ações desenvolvidas pelas secretarias estão centradas no esporte e lazer, tendo muitas destas o caráter de eventos pontuais e quando se trata de programas e projetos a concepção do esporte está reduzida à prevenção da entrada dos jovens pobres na criminalidade. Interessante notar que para tão audacioso objetivo não se encontram nos documentos analisados os indicativos de conteúdo, 
materiais, estratégias metodológicas e qualificação dos profissionais que seriam compatíveis com uma ação de qualidade socialmente referenciada.

Outro ponto observado é a fragilidade e fragmentação com que ocorrem as poucas ações voltadas à inserção profissional juvenil, desenvolvidas pela SEMJEL. As ações, "Lançamento do Programa Jovem Empreendedor" que ocorreu no dia 25 de setembro de 2014, e a "Assinatura do Convênio Minha Primeira Empresa", que ocorrera no dia 01 de julho de 2016, basicamente se referem a duas tentativas frustradas do governo na implementação de um programa que visa o empreendedorismo juvenil.

Ou seja, a opção escolhida pelo poder público municipal para tentar lidar com a questão do trabalho para os jovens Manauaras, vislumbra o investimento no programa "Minha Primeira Empresa". Pode-se identificar que em se tratando de políticas públicas de juventude para a inserção profissional, as escolhas têm focado na categoria do empreendedorismo juvenil.

A opção por políticas públicas para inserção profissional de jovens com o enfoque no empreendedorismo encontra forte crítica nos estudos de Souza (2006). Para o autor as inciativas do poder público que se baseiam na proposta empreendedora, têm sobretudo focado os jovens, e sustentam-se "na perspectiva neoliberal de que a saída para a desocupação e o desemprego está no microempreendimento da juventude e, em decorrência, na preparação e educação dos jovens para assumirem a condição de potenciais e futuros empreendedores" (SOUZA, 2006, p.119).

Nesse sentido, o autor entende que ao se trabalhar a educação empreendedora para os jovens como única alternativa ao desemprego, e aos desafios do mundo globalizado e neoliberal, é coloca-los como protagonistas empreendedores, ou seja, principais responsáveis pelo seu emprego ou pelo seu desemprego. Sendo assim, as iniciativas de inserção de jovens como empreendedores no mercado de trabalho, representaria uma forma de o capital fazer com que os jovens se encarreguem individualmente pela sua própria inserção no mercado de trabalho, pelo seu êxito ou pelo seu fracasso.

Em se tratando das políticas públicas para a inserção profissional de jovens, delineadas pela SEMJEL, não se pode analisar de fato os pressupostos teóricos que embasam a escolha da secretaria por ações que almejam o empreendedorismo juvenil. Identificou-se a intencionalidade de aplicação de um programa, mas que na verdade ainda não foi colocado em prática, uma vez que a implementação do mesmo esbarra em processos burocráticos que impossibilitam a sua execução. 
As poucas e frágeis tentativas do poder municipal, aqui identificadas, para o desenvolvimento de políticas de inserção profissional para os jovens revelam que mesmo o trabalho sendo algo importante para esse segmento, conforme apontam as pesquisas, há pouca atenção da secretaria a essa questão.

Para que o poder público possa atender as demandas juvenis, entre elas, o trabalho é necessário que se leve em consideração as reais necessidades dos jovens manauaras. Pois, como nos diz Nunes e Fernandez (2016),

Cada jovem seguirá seu percurso conforme os determinantes sociais e culturais que está inserido. Assim, é preciso que as políticas para a juventude sejam concebidas com esse olhar, respeitando as particularidades desse segmento, aliando suas necessidades aos seus direitos. A relação dos jovens com o mundo do trabalho é bastante complexa e ocorre a partir de realidades distintas; as políticas de trabalho e emprego direcionadas a este segmento devem ser construídas preservando as especificidades que são inerentes à condição juvenil (NUNES; FERNANDEZ, 2016, p. 71).

Desta forma, não se pode afirmar que as opções das políticas públicas para inserção profissional dos jovens, desenvolvidas pela SEMJEL têm sido a melhor alternativa para o atendimento das demandas da população jovem manauara, uma vez que não há uma consulta a essa população para o conhecimento de suas reais necessidades, além da baixa qualidade e alcance quantitativo das ações.

\section{Considerações finais}

A pesquisa apresenta contribuições à compreensão das políticas públicas de juventude no cenário local e revela ao mesmo tempo, o desafio de compreender a juventude na região Amazônica, não somente no que concerne às políticas públicas, mas em todos os recortes que permitam configurar as situações juvenis na Amazônia.

Diante da grandeza deste desafio, o número de pesquisas sobre a temática na região demonstra-se incipiente. A pesquisa traz uma aproximação com a realidade do Estado do Amazonas e do Município de Manaus, das quais se apura a fragilidade na proposição de políticas públicas de juventude.

A temática da juventude vem sendo objeto de investigação de diferentes áreas do conhecimento dentro das ciências sociais. Considera-se que a tarefa de pensar a educação na 
Amazônia requer também dialogar com este conteúdo produzido sobre as juventudes produzidas neste lugar.

As políticas públicas de juventude em âmbito nacional apresentam considerável avanço, porém, muitas são as dificuldades para se romper com a visão restrita de que jovem com tempo livre é sinônimo de jovem potencialmente perigoso. Com relação à inserção profissional, não é diferente, apesar de ocupar parte significativa do interesse dos jovens, há uma grande necessidade de políticas públicas que possibilitem melhores condições de vida a esses indivíduos.

Nos programas e ações desenvolvidos pela SEMJEL, é perceptível a escassez de programas e ações voltadas à inserção profissional dos jovens no município de Manaus. As atividades desenvolvidas, ao menos no período em que se dá a pesquisa, são em sua maioria voltadas ao esporte e lazer.

Existe pouca atenção à temática do trabalho, e as escassas ações voltadas a essa temática tem o foco no empreendedorismo juvenil. O que por sua vez representa a alternativa do poder público municipal para lidar com a questão da inserção profissional para os jovens no município de Manaus. Além disso, as poucas ações identificadas carecem de qualidade e continuidade.

Portanto, é preciso um olhar mais cauteloso dos poderes públicos ao atendimento das demandas juvenis, dentre as quais as políticas voltadas à inserção juvenil no mercado de trabalho, visto a importância que o trabalho ocupa na vida desse segmento, não somente pelo suporte material que a remuneração advinda de uma ocupação pode gerar, mas também por suas implicações na identidade do ser jovem.

\section{REFERÊNCIAS}

ARAÚJO, Alexandre Viana. Política pública para juventude: analisando o processo de construção no Brasil. In: Anais do IV Congresso Ibero-Americano de Política e Administração da Educação. Porto, Portugal, 2014.

ASSOCIAÇÃO DE JOVENS EMPRESÁRIOS DO AMAZONAS - AJE. Sobre a AJE-AM. Disponível em: http://comunicacao66.wixsite.com/ajeam/sobre-ajeam. Acesso em: 26 de março de 2017.

BRASIL. Lei no 11.129, de 30 de junho de 2005. Institui o Programa Nacional de Inclusão de Jovens - ProJovem; cria o Conselho Nacional da Juventude - CNJ e a Secretaria Nacional de Juventude. 
BRASIL. Emenda Constitucional no 65, de 13 de julho de 2010. Altera a denominação do Capítulo VII do Título VIII da Constituição Federal e modifica o seu art. 227, para cuidar dos interesses da juventude.

BRASIL. Lei $\mathbf{n}^{\mathbf{0}}$ 12.852, de 05 de agosto de 2013. Institui o Estatuto da Juventude e dispõe sobre os direitos dos jovens.

CONFEDERAÇÃO NACIONAL DE JOVENS EMPRESÁRIOS - CONAJE. Institucional. Disponível em: http://conaje.com.br/institucional/. Acesso em: 21 de março de 2017.

CORROCHANO, Maria Carla. Juventude e trabalho: algumas tensões nas ações públicas dirigidas a jovens no Brasil. In: ALMEIDA, Maria Isabel Mendes; LIMA, Fernanda Déborah Barbosa. Educação e Trabalho na experiência juvenil. Rio de Janeiro: Gramma, 2014. p. $13-40$.

FALCÃO, Nádia Maciel. Políticas públicas de juventude na cidade de Manaus: mapeamento de ações e análise das concepções de juventude (2005-2014). In: PINHEIRO, M. G. S. P; FALCÃO, N. M. (Orgs.). Políticas Públicas, Educação Básica e Desafios Amazônicos. Manaus: EDUA, 2016. p. 117 - 150.

FALCÃO, Nádia Maciel; CARRANO, Paulo. Condição juvenil, escola e mercado de trabalho: aproximações e distanciamento na experiência de jovens de Manaus. In: PINHEIRO, Maria das Graças Sá Peixoto; FALCÃO, Nádia Maciel. (Orgs.). Políticas Públicas, Educação Básica e Desafios Amazônicos. Manaus: EDUA, 2016. p. 151 - 180.

GUIMARÃES, Nadya Araújo. Trabalho: uma categoria-chave no imaginário juvenil? In: ABRAMO, Helena Wendel; BRANCO, Pedro Paulo M. (Orgs.). Retratos da juventude brasileira: análises de uma pesquisa nacional. São Paulo: Editora Fundação Perseu Abramo, 2008. p. $149-174$.

MANAUS/SEMJEL. Relatório de Projetos, Programas e Ações - SEMJEL (2014-2016). Manaus, 2016.

MANAUS/SEMJEL. Relatório de Projetos, Programas e Ações voltadas à inserção profissional - SEMJEL (2014-2016). Manaus, 2017.

SOUZA, Adriano Mohn. Jovens e educação empreendedora: que discurso é esse? 2006. Dissertação (Mestrado em Educação) - Universidade Católica de Goiás,Goiás, 2006.

NOVAES, Regina. Célia Reyes. Prefácio. In: CASTRO, Jorge Abrahão; AQUINO, Luzenir Maria C. de; ANDRADE, Carla Coelho de. Juventude e Políticas Sociais no Brasil. Brasília: IPEA, 2009.

NUNES, Maísa Bruna de Almeida; FERNANDEZ, Cristiane Bonfim. Estado, sociedade e políticas de trabalho e emprego voltadas para os jovens no Brasil. R. Katályses, Florianópolis, v. 19, n. 1, p. 64-72, jan./jun. 2016.

SPOSITO, Marília Pontes; CARRANO, Paulo. Juventude e políticas públicas no Brasil. Revista Brasileira de Educação. N. 24, set/out/nov/dez 2003. p. 16-39. 
SPOSITO, Marília Pontes; CORROCHANO, Maria Carla. A face oculta da transferência de renda para jovens no Brasil. Tempo Social - Revista de Sociologia da USP. V. 17, n. 2, Nov. 2005, p. 141-172.

\section{SOBRE AS AUTORAS}

\section{Nádia Maciel Falcão}

Doutora em Educação pela Universidade Federal Fluminense (UFF); professora do Programa de Pós-Graduação em Educação da Faculdade de Educação da Universidade Federal do Amazonas; membro do grupo de pesquisa Educação, Culturas e Desafios Amazônicos (UFAM). E-mail: falcao.nadia@gmail.com

\section{Rafaela Silva Marinho}

Licenciada em Pedagogia pela Universidade Federal do Amazonas (UFAM); professora da Secretaria Municipal de Educação de Manaus; membro do grupo de pesquisa Educação, Culturas e Desafios Amazônicos (UFAM). E-mail: rafaela_marinho_94@hotmail.com 